\title{
THE IMPORTANCE OF SURGICAL TRAINING IN THE AESTHETIC IMPACT OF BREAST CARE AT HOSPITAL GERAL DE PALMAS
}

Nilo Coelho Santos Júnior ${ }^{1}$, Bruno Garcia Simões Favaretto

${ }^{1}$ Universidade Federal do Tocantins - Palmas (TO), Brazil.

Objectives: In view of the prominent incidence and morbidity (especially cosmetic and psychological) associated with breast cancer, it was intended to demonstrate the evolution of the surgical approach of this pathology in women operated at the Hospital Geral de Palmas (HGP), in the pre- and post-training course in breast oncoplasty (BO) by mastologists. Methodology: A retrospective cohort study of surgery for breast cancer in women performed from July 2013 to June 2016 at the HGP. The study criteria were based on patients' identification and respective age, date of surgery, and the type of surgery, either reconstructive or radical. The number of reconstructive surgeries was compared between the period before the end of the training (pre-course, July 2013, to December 2014) and the period that followed (post-course, January 2015 to June 2016). The descriptive statistics and the comparison of the variables were analyzed using the software IBM ${ }^{\circledR}$ SPSS $^{\circledR}$ Estatistics 20.0. The Kolmogorov-Smirnov test was used for normality analysis and the one-sample chisquare test for expected distribution with one degree of freedom (DF). The association between the type of surgery and the period (pre- or post-course) was assessed with Pearson's chi-square $\left(\chi^{2}-\mathrm{P}\right)$ and its subsequent continuity correction (CC), likelihood ratio ( $\lambda \mathrm{LR}$ ), and Fisher's exact test by linear-by-linear association (FEL-LA). Significance level $\alpha=5 \%$ was adopted. Results: Records of 94 surgeries performed before and 134 after training were found. Of these, the percentage of reconstructive practices increased from 5.3\% (2013-2014) to 53.7\% (2015-2016), with a significant association with the completion of training in BO $\left(\chi^{2}-\mathrm{P}=57.891 ; \mathrm{CC}=55.747 ; \lambda \mathrm{LR}=67.533\right.$; FEL-LA=57.637; $\left.\mathrm{DF}=1 ; \mathrm{p}<0.001\right)$. Conclusion: The training in $\mathrm{BO}$ provides better aesthetic conditions and, therefore, better quality of life after surgery, in addition to allowing assistance to more patients, regardless of the plastic surgery team dedicated to oncoplastic procedures.

Keywords: Mastectomy; Breast Cancer; Mammoplasty. 